\title{
Closure of residual fistula after esophageal atresia repair in a 5-year-old using endoscopic submucosal dissection of surrounding mucosa
}

Esotracheal fistulas after esophageal atresia repair recur in 5 to $10 \%$ of cases $[1,2]$ and lead to recurrent pneumonia or mediastinitis. Several surgical techniques are effective in closing an esotracheal fistula by thoracotomy or cervicotomy [3], but endoscopic success has never been published for this indication. We present the case of a 5-year-old patient with a previous history of type III esophageal atresia neonatal surgery, chronic respiratory congestion, and poor weight gain. She experienced a fistula recurrence with a large tracheoesophageal defect (\Fig. 1).

We performed an endoscopic fistula closure after prior endoscopic submucosal dissection (ESD) of the surrounding mucosa as previously reported for a button battery-induced esotracheal fistula [4] or idiopathic chronic fistula [5]. The patient underwent tracheal intubation with balloon placement just under the fistula. ESD was assisted by clip-and-line traction to dissect deeper into the fistula tract ( $\triangleright$ Video 1 ). Once the mucosa was resected, we closed the area using four clips anchored in the submucosa. A radiological check objectified the tightness of the closure.

The postoperative consequences were favorable, marked by a disappearance of the patient's respiratory symptoms during the following 3 months. A radiological check with opacification carried out 3 months before the gesture shows a tiny residual fistula and pseudo-diverticular scarring ( $\mathbf{F i g . 2}$ ). The patient underwent a second procedure, during which ESD of the surrounding mucosa was done with deep cutting of the diverticular wall. Then, a new closure of the resected area was done. The closure of the residual fistula was confirmed by radiological control after 1 month.

Currently, the management of recurrent esotracheal fistulas after atresia surgery is not well defined. Endoscopic closure after ESD of the surrounding mucosa
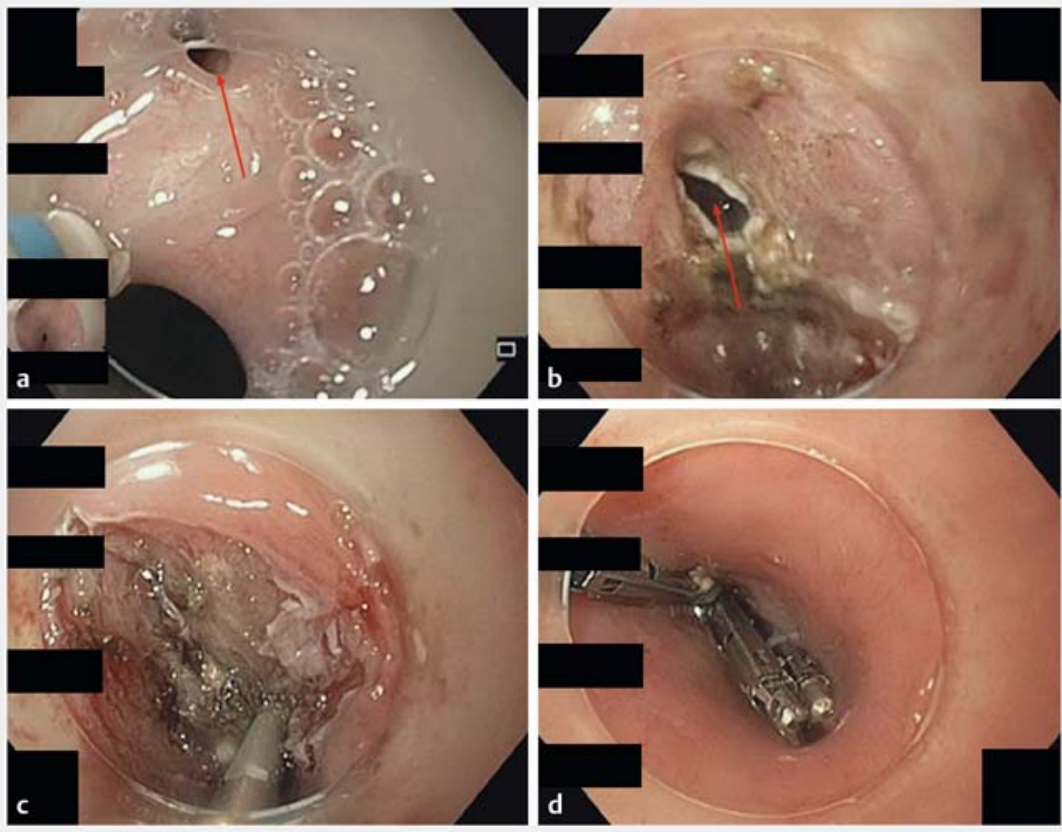

- Fig. 1 First endoscopic submucosal dissection to remove mucosa surrounding the fistula. a Appearance of the residual tracheoesophageal fistula (red arrow showing the fistula). $\mathbf{b}, \mathbf{c}$ Deep dissection of the entire fistulous tract using a clip-and-line system. $\mathbf{d}$ Clips placed in the submucosa to close the orifice.
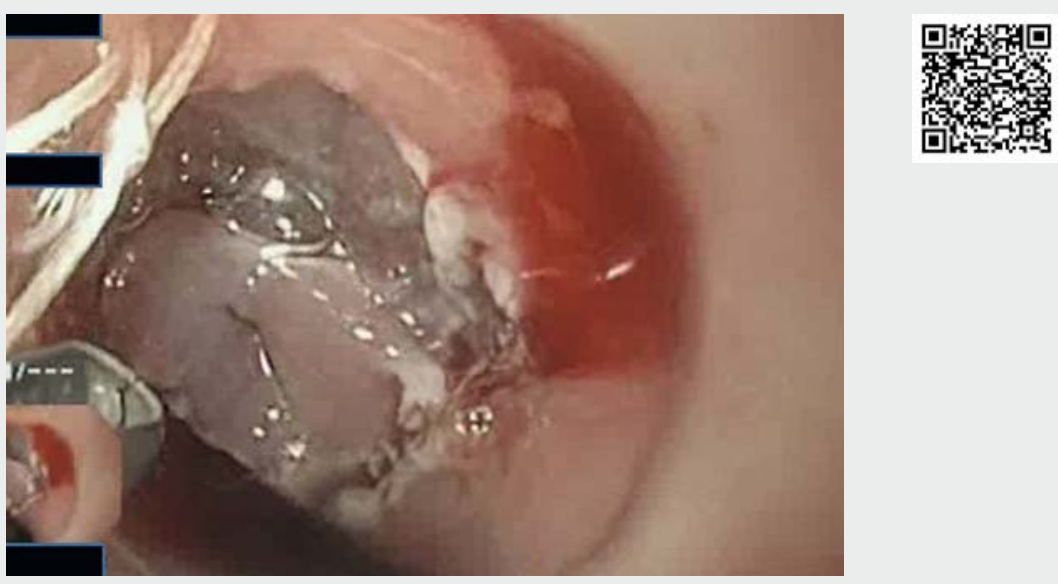

$\checkmark$ Video 1 Successful endoscopic closure of a residual fistula after esophageal atresia repair in a 5-year-old using endoscopic submucosal dissection of the surrounding mucosa. 

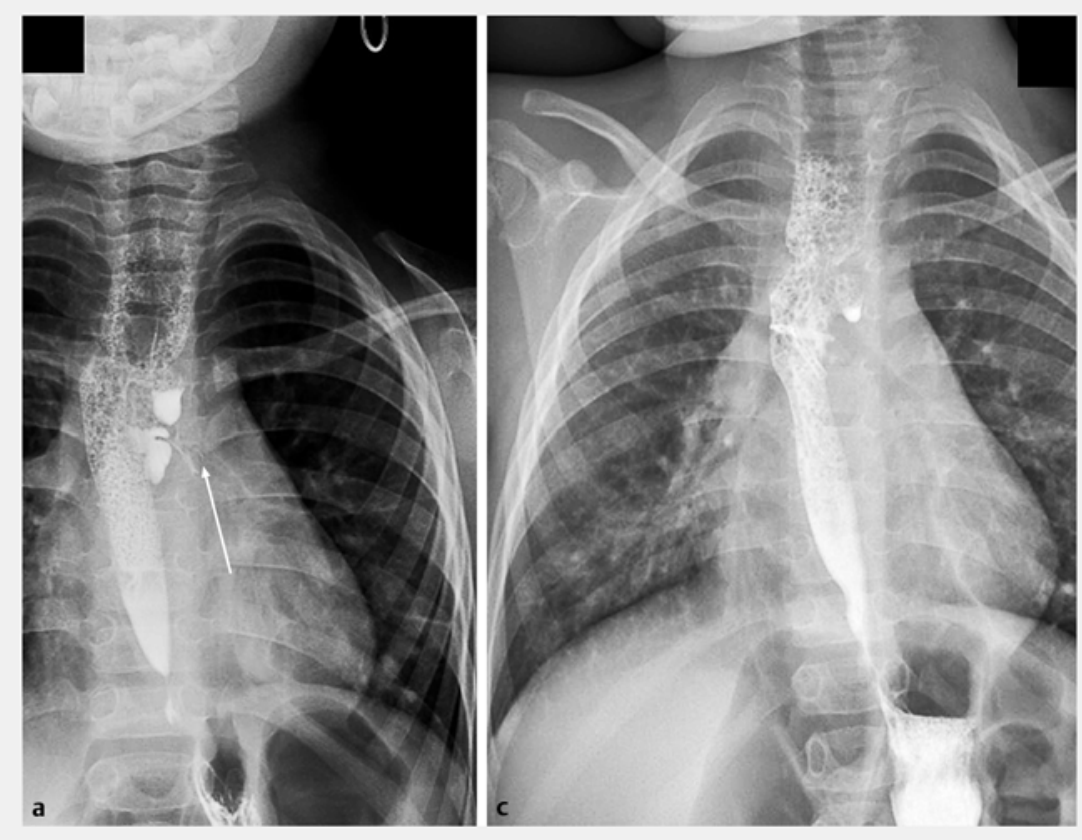

- Fig. 2 Aspect of esophageal transit before and after the second procedure. a Radiological opacification after first endoscopic closure: small residual fistula and pseudo-diverticular scarring (red arrow showing the fistula). b Radiological opacification after second endoscopic gesture: no residual fistula.

could allow a definitive resolution of the esotracheal fistulas and avoid a second risky surgery.

\section{Endoscopy UCTN_Code_TTT_1AO_2AI}

\section{Competing interests}

The authors declare that they have no conflict of interest.
The authors

Grégoire Lavaud $^{1,2}$, Sophie Heissat ${ }^{1}$, Auxane Chauveau $^{2}$, Noël Peretti ${ }^{1}$, Alain Lachaux ${ }^{1}$, Borathchakra Oung ${ }^{2}$, Mathieu Pioche ${ }^{2,3}$

1 Department of Pediatric Endoscopy and Gastroenterology, Hôpital Femme Mère Enfant, Lyon, France

2 Department of Endoscopy and Gastroenterology, Pavillon L, Edouard Herriot Hospital, Lyon, France

3 INSERM U1032, LabTau, Lyon, France

\section{Corresponding author}

\section{Dr. Mathieu Pioche}

Endoscopy Unit - Digestive Disease Department, Pavillon L - Edouard Herriot Hospital, 69437 Lyon Cedex, France Fax: +33-472-110-147

mathieu.pioche@chu-lyon.fr

\section{References}

[1] Kovesi T, Rubin S. Long-term complications of congenital esophageal atresia and/or tracheoesophageal fistula. Chest 2004; 126 : 915-925

[2] Bruch SW, Hirschl RB, Coran AG. The diagnosis and management of recurrent tracheoesophageal fistulas. J Pediatr Surg 2010; 45: 337-340

[3] Daniel S], Smith MM. Tracheoesophageal fistula: open versus endoscopic repair. Curr Opin Otolaryngol Head Neck Surg 2016; 24 510-515

[4] Gruner M, Heissat S, Pitiot V et al. Successful endoscopic closure of a refractory buttonbattery tracheoesophageal fistula in a 3 -year child using endoscopic submucosal dissection of the surrounding mucosa. Endoscopy 2017; 49: E212-E214

[5] Bertrand G, Jacques J, Rivory J et al. Deep endoscopic submucosal dissection of a refractory tracheoesophageal fistula using clip-and-line traction: a successful closure. Endoscopy 2017; 49: 1278-1280

\section{Bibliography}

Endoscopy 2021; 53: E132-E133

DOI 10.1055/a-1216-0271

ISSN 0013-726X

published online 5.8 .2020

(c) 2020. Thieme. All rights reserved.

Georg Thieme Verlag KG, Rüdigerstraße 14,

70469 Stuttgart, Germany

\section{ENDOSCOPY E-VIDEOS}

https://eref.thieme.de/e-videos

口回 Endoscopy E-Videos is a free Fection, reporting 自解: on interesting cases and new techniques in gastroenterological endoscopy. All papers include a high quality video and all contributions are freely accessible online.

This section has its own submission website at https://mc.manuscriptcentral.com/e-videos 